\title{
RESENHA
}

\section{A EDUCAÇÃO INTEGRAL: problematizando conceitos, legislação e experiências}

Debora Cristina Jeffrey ${ }^{1}$

COSTA, S. A; COLARES, M. L.S. Educação Integral: concepções e práticas a luz dos condicionantes singulares e universais. Curitiba: CRV, 2016. 204p. ISBN 978-85-444-1 $1111-7$

A educação integral, temática destacada com grande ênfase pelos governos nos anos 2000, é abordada no livro lançado no ano de 2016, a partir da problematização dos conceitos e da legislação que a embasam, bem como através de experiências desenvolvidas na região amazônica.

Sinara Almeida da Costa e Maria Lilia Imbiriba Sousa Colares, organizadoras da obra, selecionaram artigos que resultaram de pesquisas e estudos realizados à luz do Programa de Cooperação Acadêmica PROCAD - Edital n.071/2013 PROCAD/CAPES, cujo objetivo é apoiar projetos conjuntos de pesquisa entre Programas de Pós-Graduação consolidados e em consolidação.

No caso da obra, os textos são provenientes do convênio estabelecido, desde o ano de 2015, entre professores-pesquisadores da Universidade Estadual de Campinas (Programa de Pós-Graduação em Educação), Universidade do Oeste do Pará (Programa de Pós-Graduação em Educação - Mestrado) e Universidade Federal de Rondônia (Programa de Pós-Graduação em Educação - Mestrado). Esse convênio, decorrente do PROCAD, tem possibilitado o desenvolvimento da pesquisa cooperativa denominada: "As experiências pedagógicas das políticas de educação 
integral na Amazônia, constituindo, assim, uma rede de pesquisa e formação acadêmica".

Embora o PROCAD firmado entre a Unicamp, Ufopa e Unir esteja em andamento, com previsão de término no ano de 2018, o livro permite o acesso às pesquisas da rede de pesquisa e cooperação de leitores interessados na temática Educação Integral, a partir de três eixos: a legislação, as concepções e experiências amazônicas, em Educação Integral.

É interessante notar que o título da obra refere-se à denominação do termo Educação Integral, compreendendo polissemicamente a política institucionalizada no Brasil, desde os anos 2000. Porém, ao longo da obra, há uma diversidade de termos, que expressam a heterogeneidade da proposta, indicando uma tendência nacional, tais como: educação integral, educação de tempo integral, educação integral em jornada de tempo integral, escola integral, escola de tempo integral, jornada de tempo integral, educação do campo em tempo integral.

Ao contemplar esses aspectos, o livro favorece ao leitor o acesso a artigos que abordem exclusivamente, a política de educação integral e suas distintas formas de organização e espaços, contemplando a dimensão normativa, histórica e política da iniciativa, contribuindo, portanto, na problematização de elementos macro e micro educacionais.

Nesse sentido, o livro inicia esse processo de problematização com o artigo intitulado: "Quando a LDB não fala em educação integral", de autoria de Ana Elisa Spaolonzi Queiroz Assis. O texto identifica, a partir de uma análise da hermenêutica zetética, que não há uma definição de educação integral na Lei n. 9.394/96 (LDB). Apesar dessa fragilidade, a autora problematiza a expressão "tempo integral na LDB/96" e busca definir possibilidades para se estabelecer a educação integral, com base na finalidade da educação presente na legislação.

O artigo denominado "As concepções filosóficas e pedagógicas da educação integral no Brasil e as políticas educacionais", de autoria de 
Marilsa Miranda de Souza, Roberta Trevizani Aleprandi e Simone Silva Alves Trentini, analisa as concepções de educação integral, historicamente difundidas no país. Identificam quatro concepções predominantes: escolanovista, integralista, libertária-anarquista e socialista. As autoras apontam que a concepção escolanovista ainda exerce influência em iniciativas em curso, como é o caso do Programa Mais Educação.

Em "Jornada de tempo integral na educação infantil: o que dizem as pesquisas", o artigo apresentado por Talita Ananada Corrêa e Sinara Almeida da Costa, com base em levantemento de pesquisas empíricas sobre o atendimento de educação integral em jornada de tempo integral, no Brasil. Evidenciou-se que as políticas de educação infantil em jornada de tempo interal possibilitam o desenvolvimento da criança, garantindo o seu direito e especificidades. Porém, as pesquisas analisadas pelas autoras, apontam as fragilidades na oferta de educação integral em jornada de tempo integral, na educação infantil, como a falta de recursos, estrutura física adequada, desvio de funções, ausência de formação continuada, entre outros aspectos, sendo ainda uma problemática a ser superada.

O artigo "Avanços e desafios de um currículo integrado para o ensino médio brasileiro: apontamentos para uma educação integral de inspiração politécnica", de autoria de Raimunda Adriana Maia Costa, Luís Alípio Gomes e Tânia Suely Azevedo Brasileiro, analisa os avanços e desafios do currículo integrado, considerando a universalização do ensino médio e suas diferentes modalidades. Problematizam a possibilidade de construção de um currículo integrado, com o propósito de garantir a formação humana integral de inspiração politécnica, a partir do trabalho como princípio educacional.

"O conceito de educação integral, educação em tempo integral: desafios para o Plano Nacional de Educação" é artigo produzido por Sandra Fernandes Leite e Janaína Guerreiro, que busca identificar a concepção dos termos educação integral e educação de tempo integral, presentes no Plano Nacional de Educação - Lei n. 13.005/2014. 
O artigo de Rosana Ramos de Souza e Anselmo Alencar Colares intitulado: "Interfaces na formação continuada de professores para a escola de tempo integral" propõe uma reflexão, com base na Política Nacional de Educação de Tempo Integral, do processo de formação dos professores para a escola de tempo integral. Evidenciam que, apesar da implementação de ampliação da jornada escolar, as ações envolvendo a formação de professores (inicial e continuada) pelo Ministério da Educação (MEC), Secretarias Estaduais de Educação e escolas, ainda tem sido pontuais e fragmentadas, fato que desconsidera os desafios postos aos profissionais da educação, no que tange ao atendimento da população escolar diante da configuração de novos tempos/espaços e a necessidade de desenvolvimento de uma proposta curricular integrada.

Os últimos artigos presentes no livro destacam a análise da política de educação integral e de tempo integral em curso no município de Santarém (PA), no contexto da educação do campo, experiência pedagógica e ressignificação do currículo escolar pela Secretaria Municipal de Educação.

A esse respeito, o artigo denominado "O cenário da educação do campo no estado do Pará e a Política Nacional de Educação em Tempo Integral: uma realidade complexa", de autoria de Maria de Fátim Matos de Souza, Maria José Aviz do Rosário e Marinete Costa de Lima, problematizam o processo de implantação da política de educação integral no campo e como este processo está legalmente fundamentado, acompanhando as metas indicadas no Plano Nacional de Educação - Lei 13.005/2014.

Maria Aparecida dos Santos Pereira, Clênya Ruth Alves Bentes e Solange Helena Ximenes-Rocha, aprofundam o debate acerca da educação do campo em tempo integral, em artigo intitulado: "Política de Educação Integral para a escola do campo: a experiência da escola Irmã Dorothy Mae Stang". Ao analisar o processo de implantação da escola do campo de tempo integral, da unidade escolar, a partir da percepção dos profissionais da educação e comunidade escolar, evidenciou-se que apesar da existência de uma infraestrutura planejada para atender as 
especificidades educacionais, a falta de investimento na aquisição de material didático, merenda escolar e a oferta de baixos salários, acabam por comprometer o desenvolvimento da proposta pedagógica, prejudicando o cumprimento da política de educação integral proposta, bem como das metas propostas pelo Plano Nacional de Educação - Lei n.13.005/2014.

Já o artigo denominado "Educação de Tempo Integral em Santarém: ressignificação curricular na Secretaria Municipal de Educação", de autoria de Gerusa Vidal Ferreira e Maria Lilia Imbiriba Sousa Colares, apresenta as ações realizadas pela Secretaria Municipal de Educação de Santarém Semed, entre os anos de 2008 e 2014, em especial no processo de ressignificação do currículo escolar na perspectiva da política nacional de educação integral. As autoras ao realizarem a análise desse processo, compreendem que a Semed instituiu ações de ampliação de jornada escolar, sendo induzido pela adoção de programas federais. Esses programas federais, por sua vez, levaram a ressignificação curricular, a partir da ampliação dos conteúdos e tempos escolares, sem que houvesse uma integração com o currículo oficial, levando à dicotomia entre as atividades realizdas durante o turno e o contraturno escolar, aprendizagem e recreação.

Como se pode evidenciar, a obra reúne artigos que apontam o descompasso existente entre a política nacional de educação integral, a legislação que a embasa e o processo de indução da medida pelo Governo Federal, nos últimos anos. Os autores, por sua vez, preocupam-se em indicar que a adoção de medidas pontuais, a difusão de conceitos polissêmicos vinculados a concepção de educação integral de cunho liberal, reafirmam - caráter pragmático da iniciativa, contrardizendo o pressuposto de formação humana integral, sem com isso favorecer mudanças a cultura educacional, escolar, curricular, assim como dos tempos e espaços de unidades educacaionais. 
Apesar dos professores-pesquisadores apontarem as fragilidades e possibilidades para a efetividade da política de educação integral, faz-se necessário salientar a importância do PROCAD/CAPES, para a constituição da rede de pesquisa e cooperação, a fim de favorecer a difusão, bem como a integração de pesquisas, grupos de pesquisa, estudantes de cursos de graduação e pós-graduação de universidades públicas, contribuindo à difusão da produção científica nacional.

Recebida em: Março de 2017 Aprovada em: Maio de 2017 